TERRA. Revista de Desarrollo Local e-ISSN: 2386-9968

Número 7 (2020), 292-298

DOI 10.7203/terra.7.19145

IIDL - Instituto Interuniversitario de Desarrollo Local

\title{
El Pla de Dinamització i Governança Turística de La Safor (Valencia): una bona oportunitat practica per al desenvolupament local
}

\author{
Pau Pérez Ledo \\ Profe. Asociado del Dpto. de Sociología y Antropología Social (Universidad de \\ Valencia, España). Gerente del PDGT de La SAFOR \\ pau.perez-ledo@uv.es \\ https://orcid.org/0000-0001-6542-4179
}

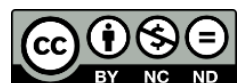

Esta obra se distribuye con la licencia Creative Commons Reconocimiento-NoComercial-SinObraDerivada 4.0 Internacional 


\title{
SECCIÓN EXPERIENCIAS Y BUENAS PRÁCTICAS
}

\author{
El Pla de Dinamització i Governança Turística de La Safor (Valencia): una bona oportunitat \\ practica per al desenvolupament local
}

Resumen: El Pla de Governança i Dinamització Turística (PGDT) de La Safor (Valencia) pretenia impulsar les línies de treball al voltant del sector turístic que es venien desenvolupant anteriorment en els diferents municipis de la comarca, per a dotar d'una visió territorial comarcal a l'estratègia turística de la zona, consensuant les línies de treball i les actuacions no solament amb altres administracions locals, sinó també amb actors del sector privat i associacions relacionades amb el sector turístic. El Pla també estava centrat en la detecció de recursos amb potencial turístic que estiguessin infrautilitzats o fossin susceptibles de ser posats en valor, prestant especial atenció a entorns que poguessin ser revaloritzats, però que en el seu estat actual no aportaven valor al sector turístic. També es posava l'accent en la generació i creació de productes i paquets turístics, treballant sobre recursos que existien actualment però que no eren atractius per a la demanda turística, amb la finalitat de produir una millora i que poguessin ser competitius. Es va treballar especialment en productes de turisme actiu, natural, gastronòmic, amb una intensa acció tecnològica. El Pla constava en el seu inici d'un desenvolupament de tres anys. Tres anys orientats a recaptar tota la informació necessària per a poder elaborar un pla estratègic que recollís les diferents visions del sector turístic, detallar totes les actuacions a realitzar, i per descomptat, executar-les. Encara que el Pla comportava una inversió per part de les principals entitats participants, l'objectiu era crear una xarxa que transcendís l'àmbit espacial del propi Pla i de la inversió inicial, i que servís de motor per a continuar treballant de manera conjunta tant el sector públic com el privat al llarg dels anys. El PGDT de La Safor es va implementar en dos de les tres anualitats en que es va projectar. No obstant això, queda moltíssima feina per fer, però ha aconseguit atorgar la identitat suficient al conjunt de la comarca del Camp de Safor per a poder promocionar-se com a destí cohesionat, creant sinergies entre els recursos.

Palabras clave: Turisme, polítiques públiques, desenvolupament local.

Recibido: 27 de noviembre de 2020

Devuelto para revisión: -

Aceptado: 02 de diciembre de 2020

\section{Referencia / Citation:}

Pérez Ledo, P. (2020). El Pla de Dinamització i Governança Turística de La Safor (Valencia): una bona oportunitat practica per al desenvolupament local. TERRA. Revista de Desarrollo Local, (7), 292-298. DOI 10.7203/terra.7.19145 


\section{INTRODUCCIÓ}

Els Plans de Governança i Dinamització Turística s'han desenvolupat en diferents comarques de la Comunitat Valenciana durant els últims anys, i suposen una suma d'esforços per part de tots els actors turístics d'un territori. Es tracta d'una visió per a abordar el desenvolupament turístic de manera estratègica, planificada i des d'un punt de partida supramunicipal, tractant de superar la escala local i assentar-se a una escala comarcal, de manera que s'estableixin i es treballin els objectius de manera conjunta (Farinós et al., 2018). Aquests plans contribueixen al reequilibri entre els espais litorals, tradicionalment més dinàmics i competitiu,s amb els territoris d'interior, que en l'actualitat ostenten un major marge de desenvolupament i creixement.

La comarca de La Safor es mostra al visitant a través d'un atractiu territori dividit entre el paisatge de la costa i l'interior muntanyenc. Les altes serres de Mustalla, Safor, Agulles i Grossa, formen un cèrcol natural de rica vegetació, mentre que el litoral acull en la seva planícia horts, àmplies i acollidores platges i una concentració urbana d'alta densitat. La proximitat i les múltiples relacions entre si de les poblacions que integren la comarca, fan que la Safor es pugui considerar com un conjunt urbà, com una ciutat dispersa, envoltada de zones verdes, dedicades en la seva majoria al cultiu de la taronja. Cimeres situades a poca distància de la mar, camps de tarongers que s'amaguen entre els vessants de les muntanyes, amples horitzons que es fundeixen amb la línia de la platja, constitueixen alguns elements del paisatge de La Safor, una comarca que sorpren per la varietat de paisatges que van des de la costa a l'interior.

Des de la Mancomunitat de Municipis de La Safor, han hagut diversos intents d'harmonitzar una política turística comarcal consensuada. La principal acció anterior a estos plans va ser la Creació del Consorci Turístic Cultural de La Safor al 2009 que seria objetcte d'una altra reflexió.

El PDGT de la Safor ha tingut una vigència de tres anualitats i s'han executat dos de les tres anualitats projectades. Els objectius generals del PDGT expressats a les memòries eren:

a) Crear una destinació turística madura: participació i posicionament territorial, innovació, qualitat i sostenibilitat.

b) Desestacionalitzar l'activitat turística i contribuir al reequilibri socioterritorial.

c) Generar una oferta atractiva més enllà del model de sol i platja, i promoure-la de manera adequada.

d) Crear nous productes turístics i experiències que ajuden a desestacionalitzar i diversificar l'oferta.

e) Redirigir els fluxos cap a altres zones oferint activitats atractives que complementen el dia de platja: visites al Parc Natural, rutes en bicicleta, culturals, naturals i gastronòmiques, albirament d'aus, excursions a monuments, museus, activitats a la platja orientades a la sensibilizació ambiental i cultural...

Sobre estes bases es feia una reflexió des de l'àmbit de la gestió pública comarcal sobre la necessitat de superar la escala territorial local per coordinar les polítiques a escala comarcal, i es demandava la creació d’una identitat compartida i una marca que agrupara la comarca. 


\section{LA PRIMERA ANUALITAT: 2017}

Des de les polítiques públiques es plantejava la necessitat de crear unes eines bàsiques de comunicació del PDGT, una marca i un llenguatge comú. Era una anualitat que marcava uns inicis (Taula 1).

Taula 1. Principals actuacions del PDGT de La Safor (2017)

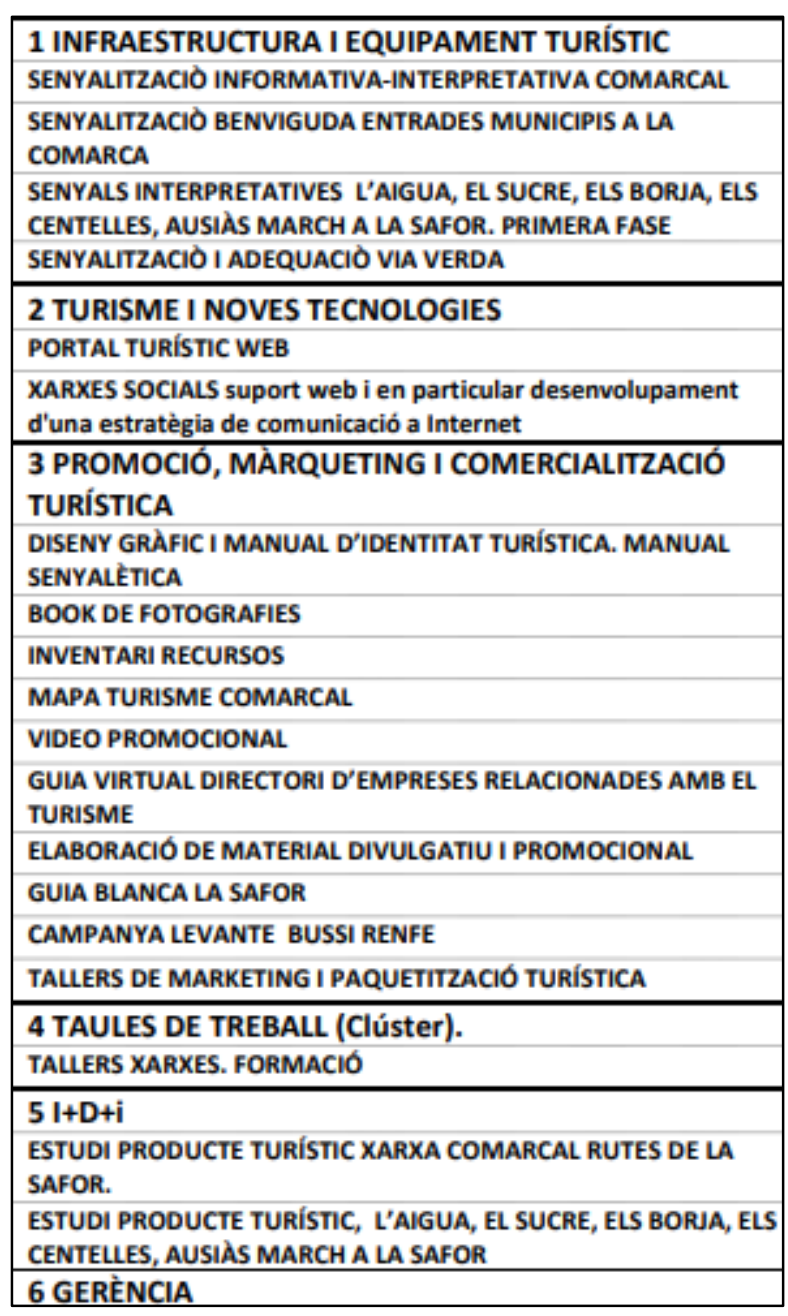

Font: PDGT de La Safor, 2017.

El conjunt de les actuacions va suposar una acció valorada en 210.000 euros, dels quals es va executar una bona part amb no poques dificultats basades en la complexitat per a contractar i justificar les despeses. Així i tot, l'acció i l'esforç realitzat va estar molt ben valorades per les administracions signants del conveni i els agents implicats.

\section{LA SEGONA ANUALITAT: 2018}

La Segona anualitat va resultar la darrera anualitat del Pla executada pel seu nivell d'execució. Al marc d'ella es va realitzar una selecció d'accions de les inicialment 
projectades, degut a les dificultats administratives a l'hora d'actuar. Tot i això es van executar una sèrie de projectes molt ben valorats (Taula 2).

Figura 2. Quadre resum de part de les propostes actuacions (2018)

\begin{tabular}{|c|c|}
\hline \multirow{2}{*}{$\begin{array}{l}\text { 1. Infraestructura } \quad \text { i } \\
\text { equipament turístic }\end{array}$} & Camí antic trenet segona fase \\
\hline & $\begin{array}{l}\text { Adequació rutes ciclo-peatonal comarcal(descobreix La Safor, de la } \\
\text { platja a l'interior }\end{array}$ \\
\hline & $\begin{array}{l}\text { Interpretació ruta comarcal l'aigua, el sucre, els Borja, els Centelles, } \\
\text { Ausiàs March a La Safor (segona fase) }\end{array}$ \\
\hline & Acondicionament miradors-paisatges de La Safor \\
\hline \multirow[t]{3}{*}{$\begin{array}{l}\text { 2. Turisme i noves } \\
\text { tecnologies }\end{array}$} & Aplicacions per a mòbils \\
\hline & Xarxes socials \\
\hline & Traducció web ampliació \\
\hline \multirow{15}{*}{$\begin{array}{l}\text { 3. Promoció, màrqueting i } \\
\text { comercialització turística }\end{array}$} & Elaboració de material divulgatiu i promocional \\
\hline & Guia senders La Safor \\
\hline & Fullets festivals promoció \\
\hline & Fullets turisme actiu \\
\hline & Fullets horaris museus i monuments \\
\hline & Fullet senders \\
\hline & Fullet rutes gastronomia \\
\hline & Fullets dels porrats \\
\hline & Fullets entre comarques \\
\hline & Campanya Levante bussi Renfe... \\
\hline & $\begin{array}{l}\text { Lloguer lloc per a esdeveniments puntuals- promoció recursos-empreses } \\
\text { turístiques-productes }\end{array}$ \\
\hline & Promoció en revistes \\
\hline & Promoció esdeveniments esportius i culturals \\
\hline & Promoció fires \\
\hline & Tallers creació productes turístics \\
\hline 4. Taules de treball & Tallers xarxes. Formació \\
\hline \multirow[t]{2}{*}{ 5. $i+d+i$} & $\begin{array}{l}\text { Estudi rutes ciclo-peatonal comarcal culturals i naturals (descobreix La } \\
\text { Safor, de la platja a l'interior) }\end{array}$ \\
\hline & Estudi i diagnòstic dels senders de La Safor \\
\hline 6. Gerència & \\
\hline
\end{tabular}

Font: PDGT de La Safor, 2018.

D’aquest quadre d'actuacions van tindre especial rellevància l'edició del fullet de gastronomia, la gestió esportiva i el balcó de La Safor a Ador, així com els punts d'avistament d'aus que es van realitzar al Serpis i a la marjal de Xeresa.

\section{LA TERCERA ANUALITAT: 2019}

La tercera anualitat va suposar un intent que finalment no es va desplegar, ja que des de la pròpia mancomunitat es va estimar que sobrepassava els límits de la pròpia organització. Era la anualitat més ambiciosa i que suposava plasmar en el territori les accions del Pla (Taula 3). 
Taula 3. Principals actuacions del PDGT de La Safor (2019)

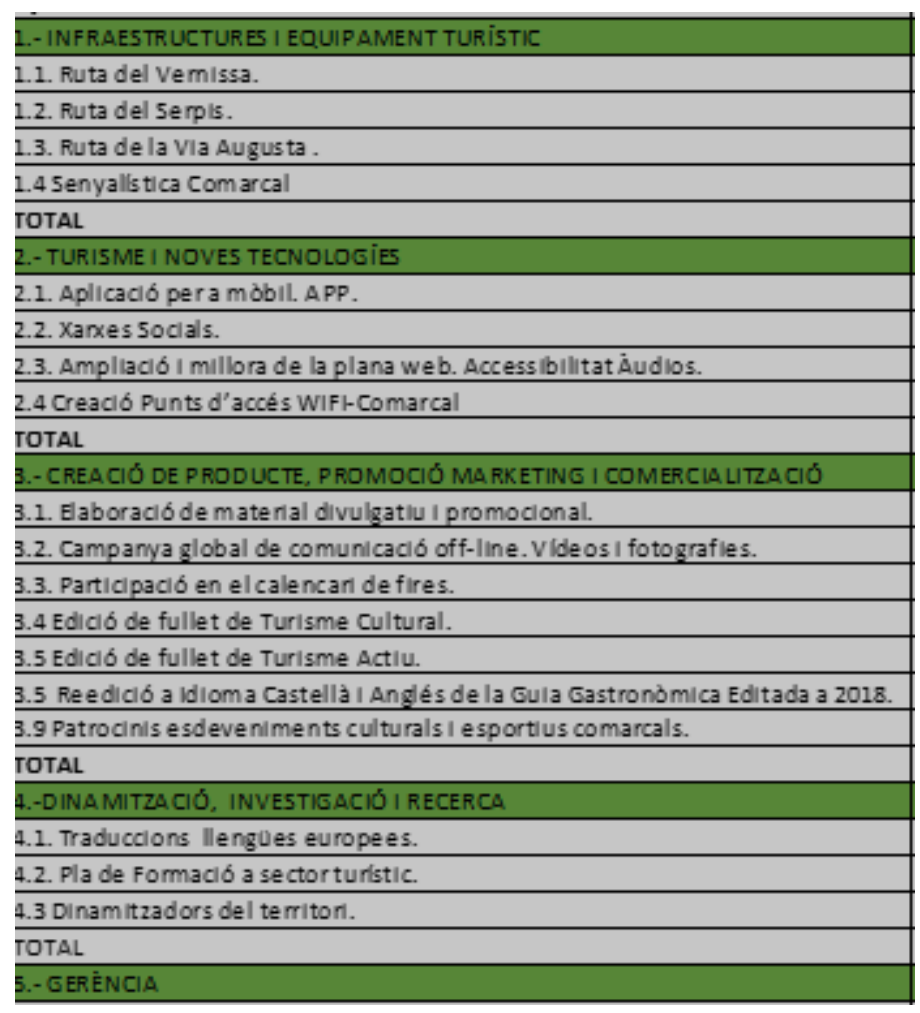

Font: PDGT de La Safor, 2019.

Tot i això, esl projectes han estat desenvolupats des d'altres intàncies de l'administració o des de la pròpia Mancomunitat com a gestió directa. Queda per tant, la necessitat d'impulsar estos programes en accions futures.

\section{REFLEXIÓN FINAL}

Si calgués destacar algun dels aspectes del PGDT de La Safor, aquest seria el seu plantejament de treball conjunt i de cooperació entre els municipis i les administracions. Quan parlem de desenvolupament local, l'activitat econòmica, la identitat d'un territori, els seus recursos, llocs, cultura i valors intangibles no es limiten únicament a un terme municipal com a tal, sinó que són la suma de tot el territori, podent aquest estar format per multitud de municipis. En eixe sentit el PGDT de La Safor ha servit per crear un llenguatge comú al voltant del turisme, una marca que ha aglutinat el turisme comarcal i una serie d'accions de comunicació, promoció i marketing que han mantés una continuïtat en el temps.

A l'hora de desenvolupar aquest tipus de plans, i tenint en compte que per a la consecució dels objectius amb èxit és necessària la col-laboració de multitud d'agents, és imprescindible pensar en xarxa, treballar de manera supramunicipal, establir contactes de treball fluids, i que tots els actors estiguin informats dels processos, accions que es desenvolupen i que a més vagin aportant activament a aquest pla conjunt.

A vegades, el que a priori sembla la tasca més fàcil, que és la comunicació, és la que determina l'èxit o el fracàs d'aquesta mena d'accions. El saber recollir adequadament les necessitats del territori, conèixer les possibilitats i limitacions d'aquest, així com 
assegurar-se que tot el dissenyat en el pla s'implanta i es realitzen accions als municipis, vertebrant el territori, és essencial perquè un PDGT com l'aquí exposat pugui arribar a bon port.

Per tot això, la suma d'esforços i el determinar conjuntament la direcció a prendre, és el que produeix els efectes tangibles i cohesiona l'estratègia turística de tots els municipis de la comarca, que tan bé es complementen entre si, amb la fortalesa actual del turisme de sol i platja, però sumant tot el potencial quant a turisme esportiu i natural de la zona interior de la comarca. La suma de tots els recursos permet una diversificació del producte turístic que fa que el destí sigui molt més atractiu, permet ser pròxims a noves tipologies de turista, ser presents en nous mercats i, en definitiva, ser molt més competitius, que és un dels objectius principals del pla.

La no execució de la trecera anualitat ha estat la principal mancança del PDGT de La Safor. Els motius de la no execució els hem de buscar als canvis de representants polítics que van emanar de les eleccions locals de 2019, les dificultats de gestió administratives centrades en el procés de contractació pública i amb les limitacions de la pròpia organització de la mancomunitat, que van dur a la decissió final de la no execució de la tercera anualitat i es va decidir seguir dinamitzant turísticament la comarca des de les eines i accions realitzades a les anualitats 2017 i 2018. Amb tot, el balanç que es fa des de la pròpia administració comarcal és un balanç positiu.

\section{REFERENCIES}

Farinós, J., Monteserín, O., y Escribano, J. (2018). Cooperación territorial y desarrollo: una mirada desde la escala transregional y de los espacios metropolitanos, rurales y turísticos. Redes: Revista do Desenvolvimento Regional, 23 (3), 35-65. 